\title{
PENGEMBANGAN ALAT PENILAIAN KOGNITIF HASIL BELAJAR GEOMETRI DATAR BERBASIS ANDROID UNTUK MATA KULIAH PEMBELAJARAN GEOMETRI DAN PENGUKURAN
}

\author{
Elok Fariha Sari, Nursiwi Nugraheni, Busyairi
}

Universitas Negeri Semarang

\section{Kata Kunci :}

Alat Penilaian, Geometri Datar, Android

\begin{abstract}
The purpose of this study was to describe the process of developing cognitive assessment of learning outcomes of android-based flat geometry for geometry and measurement learning subjects. This research is a research development. The method used in this study is the development method with the ADDIE model. The results of this development are a description of the process of developing an Android-based flat geoet learning learning tool that includes analysis, design, development, implementation and evaluation. The contribution of this research is expected to be used as one of the references to complete the assessment on geometry and $S D$ measurement subjects, so that they are more time efficient and interesting. The theoretical benefits of the results of this study are expected to contribute to the development of geometry assessment research and as a reference for further research, especially those relating to the assessment of learning geometry.
\end{abstract}

Email penulis:

elok_pgsd@mail.unnes.ac.id

\begin{abstract}
ABSTRAK
Tujuan Penelitian ini adalah mendeskripsikan proses pengembangan penilaian kognitif hasil belajar geometri datar berbasis android untuk mata kuliah pembelajaran geometri dan pengukuran. Penelitian ini adalah penelitan pengembangan. Metode yang digunakan dalam penelitian ini adalah metode pengembangan dengan model ADDIE. Hasil dari pengembangan ini adalah deskripsi proses pengembangan alat penelitian kognitif hasil belajar geoetri datar berbasis android yang meliputi analisis, perancangan, pengembangan, implementasi dan evaluasi. Kontribusi penelitian ini diharapkan dapat digunakan sebagai salah satu referensi untuk melengkapi penilaian pada mata kuliah geometri dan Pengukuran SD, supaya lebih efisian waktu dan menarik. Manfaat teoretis dari hasil penelitian ini diharapkan dapat memberikan sumbangan bagi pengembangan penelitian penilaian geometri dan sebagai acuan penelitian selanjutnya, khususnya yang berkaitan dengan penilaian pembelajaran geometri.
\end{abstract}

\section{PENDAHULUAN}

Geometri sering digunakan dalam kehidupan nyata. Namun dalam mempelajari makna geometri yang abstrak, perlu penyesuaian dengan media yang akan dikembangkan. Menurut Irkham,dkk (2014) untuk mengeksplorasi konsep abstrak matematika tentang geometri, 
maka konsep pelajaran geometri transformasi harus benar-benar dikuasai oleh siswa. Akan tetapi, memahami konsep geometri transformasi masih sulit bagi siswa . Media diperlukan tidak hanya untuk menyampaikan konsep geometri, tetapi media juga diperlukan dalam pemberian soal evaluasi geometri.

Saat pelaksanaan evaluasi kognitif, banyak kertas yang dibutuhkan mahasiswa dalam mengerjakannya. Kertas itu berfungsi untuk lembar soal, lembar jawaban. Semakin hari kertas tersebut hanya menumpuk. Program konservasi UNNES yang mengedepankan paperless sangat cocok diterapkan untuk mengatassi masalah ini. Tentunya dengan memanfaatkan teknologi yang berkembang saat ini.

Era globalisasi ditandai dengan teknologi yang meningkat pesat. Begitu juga dengan teknologi dibidang pendidikan. Peningkatan hampir terjadi di semua bidang pendidikan. Bidang pendidikan memerlukan fasilitas yang canggih untuk menunjang proses belajar mengajar. Sehingga perkembangan teknologi sangat penting keberadaannya. Penggunaan teknologi terbukti dapat meningkatkan minat belajar anak karena tampilan yang lebih menarik sehingga akan terhindar dari rasa jenuh selama mengikuti pelajaran. Dalam hal ini minat belajar berpengaruh dalam prestasi belajar sesuai dengan penelitian Rusmini (2017) yang menyatakan bahwa Angka indeks korelasi minat belajar dengan prestasi belajar adalah 0,681 . Hasil penelitian Rusmini juga didukung penuh oleh oleh penelitian lain yang menyatakan ada pengaruh yang signifikan antara minat belajar siswa dalam hal perasaan senang, perhatian dan kemauan secara bersama-sama terhadap prestasi belajar siswa dengan hubungan positif antara minat belajar siswa dalam hal perasaan senang, perhatian dan kemauan secara bersama-sama dengan prestasi belajar pada mata pelajaran matematika (Yustinus, 2017).

Peran teknologi pun sangat berpengaruh untuk menghemat kertas dan waktu mengoreksi. Berdasarkan ilustrasi di atas, maka dosen perlu mengembangankan media penilaian soal kognitif geometri untuk mahasiswa PGSD FIP UNNES. Untuk memenuhi kebutuhan tersebut, maka akan diteliti pengembangan penilaian kognitif hasil belajar geometri datar berbasis android untuk mata kuliah pembelajaran geometri dan pengukuran.

\section{METODE PENELITIAN}

Metode yang digunakan dalam penelitian ini adalah metode pengembangan model ADDIE (Analysis, Desaign, Development, Implementation, Evaluation). Menurut Lee \& Owens (2004) model pengembangan ADDIE terdiri dari 5 tahap :

\section{a. Analysis (Analisis)}

Ada beberapa hal yang dianalisis dalam tahap ini yaitu :

(1) Kurikulum Jurusan PGSD pada semester genap tahun 2017/2018 masih menggunakan kurikulum UNNES tahun 2015. Adapun bahan kajian dalam perkuliahannya tertuang dalam RPS (lampiran). (2) Karakteristik mahasiswa jurusan PGSD, dilihat dari sudut pandang gaya belajar, $100 \%$ mahasiswa telah menggunakan handphone untuk menunjang belajar mereka. (3) Pengembangan alat penilaian berbasis Android ini dipergunakan untuk mahasiswa jurusan PGSD UNNES.

\section{b. Design (Desain)}

Tahap ini meliputi penyusunan kerangka struktur isi program, menyusun garis-garis besar isi program media. Untuk program interaktif terlebih dahulu dibuat flowchart (Sutopo, 2003, hlm. 34). Flowchart view adalah diagram yang memberikan 
gambaran alir dari satu tampilan ke tampilan lainnya. Pembuatan flowchart bertujuan agar dalam pembuatan media lenih terarah dan tidak mengakibatkan keluar dari konsep.

c. Development (Pengembangan)

Dalam tahap ini dilakukan pembuatan media yang dilakukan dengan mengambil gambar, merekam, membuat animasi, menyusun teks, dsb. Dilanjutkan dengan proses pemrograman dengan authoring tools, pengemasan/formatting, pengkajian/penyuntingan.

\section{d. Implementation (Implementasi)}

Pada tahap ini media yang telah dibuat di uji cobakan di lapangan untuk mengetahui keterbacaan dan keefektifan media dalam pembelajaran.

e. Evaluation (Evaluasi)

Pada tahap ini media di evaluasi, apakah media yang dikembangkan dapat mencapai tujuan-tujuan yang ditetapkan dalam pembelajaran atau tidak.

\section{HASIL DAN PEMBAHASAN}

Hasil pengembangan alat penilaian berbasis android pada pokok bahasan geometri datar ini berupa 2 hal, yaitu deskripsi pengembangan dan produk aplikasi alat penilaian, yang selanjutnya dinamakan aplikasi 'Apel Geometri' yang merupakan singkatan dari alat penilaian geometri. Pengembangan ini menggunakan model pengembangan ADDIE. Model pengembangan ini dilakukan dalam lima tahapan, yaitu: analysis (analisis), design (perancangan), development (pengembangan), implementation (implementasi), evaluation (evaluasi). Berikut akan dipaparkan proses pengembangan sekaligus produk pengembangannya.

\section{a. Analysis (analisis)}

Hal-hal yang dianalisis peneliti meliputi analisis kurikulum, analisis situasi, analisis karakteristik siswa.

- Analisis kurikulum dan materi pembelajaran

Dalam penyusunan alat penilaian memerlukan análisis kurikulum jurusan PGSD dan materi pada mata kuliah pembelajaran geometri dan pengukuran. Analisis kurikulum dilakukan untuk menentukan penilaian apa yang yang paling dibutuhkan untuk dilakukan pengembangan penilaian dengan menggunakan android.

Pemilihan materi dilakukan melalui diskusi dengan pengampu mata kuliah pembelajaran matematika lainnya. Dari hasil diskusi, materi geometri datar dirasa perlu dilakukan pengembangan alat penilaian yang berbasis android. Selanjutnya analisis RPS dilakukan untuk mata kuliah pembelajaran geometri dan pengukuran. Berikut contoh bagian dari RPS 


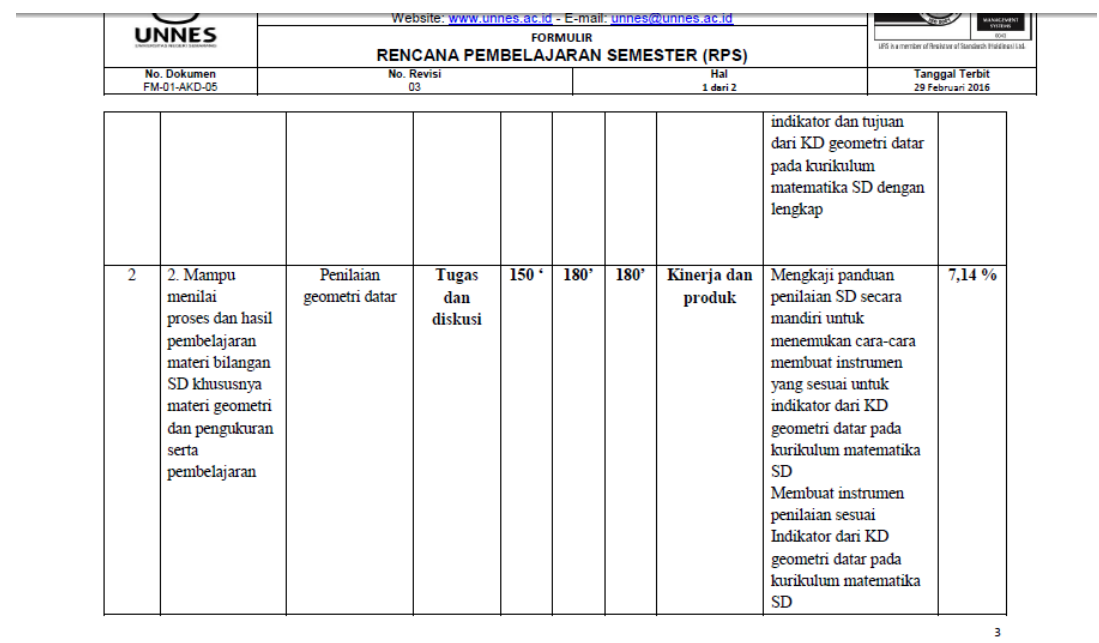

Kemampuan yang diharapkan dari pemebelajaran geometri dan pengukuran, salah satunya adalah mampu menilai proses dan hasil pembelajaran materi bilangan SD khususnya materi geometri dan pengukuran serta pembelajaran.

- Analisis situasi dan karakteristik mahasiswa.

Analisis situasi dilakukan di Jurusan PGSD UNNES, sebagai tempat uji coba produk. Analisis ini melalui observasi dan wawancara dengan mahasiswa matematika. Hasil analisis situasi di Jurusan PGSD adalah sebagai berikut:

1) Semua mahasiswa mempunyai handphone pribadi, dengan spesifikasi 95\% android dan 5\% iphone.

2) Mahasiswa menggunakan handphone untuk menunjang proses belajar.

3) Mahasiswa mahir menggunakan handphone.

4) Dosen masih menggunakan media kertas untuk penilaian kognitif.

Berdasarkan keterangan di atas, maka dapat dikatakan bahwa pengembangan alat penilaian berbasis android perlu dilakukan di Jurusan PGSD FP UNNES.

\section{b. Design (Perancangan)}

Tahap selanjutnya adalah mendesain alat penilaian yang akan dibuat berdasarkan hasil analisis. Desain yang dilakukan yaitu membuat rancangan pengembangan alat penilaian untuk pokok bahasan geometri datar yang berupa flowchart. Penyusunan rancangan pengembangan ini bertujuan untuk menggambarkan keseluruhan isi media pembelajaran yang akan dibuat. Pembuatan flowchart ini bertujuan untuk mempermudah proses pengembangan dalam menggabungkan komponen-komponen media yang ada.

Setelah pembuatan rancangan pengembangan penilaian dan flow chart selesai, kegiatan yang dilakukan yaitu menentukan spesifikasi handphone yang mampu menjalankan aplikasi penilaian ini.

Rancangan pengembangan aplikasi penilaian tersebut selanjutnya dikonsultasikan kepada dosen ahli untuk memperoleh saran dan persetujuan untuk dikembangkan lebih lanjut. 


\section{c. Development (Pengembangan)}

Pada tahap pengembangan ini rancangan pengembangan, flowchart yang telah dibuat akan dikembangkan menjadi sebuah aplikasi. Untuk mengembangkan digunakan authoring tool Adobe Flash Proses pengembangan diawali dengan pembuatan template dan mengumpulkan komponen-komponen, yaitu dengan membuat background, gambar-gambar (image), teks, tombol navigasi.

Aplikasi penilaian berbasis android yang dikembangkan terdiri dari 3 bagian yaitu pendahuluan, inti, dan penutup. Pendahuluan berisi judul, logo UNNES, identitas jurusan, petunjuk, isi data dan profil pengembang serta tombol keluar. Bagian inti meliputi sepuluh pilihan menu utama yaitu nomor latihan soal. Bagian Penutup berisi skor akhir.

Berikut disajikan hasil contoh pengembangan:

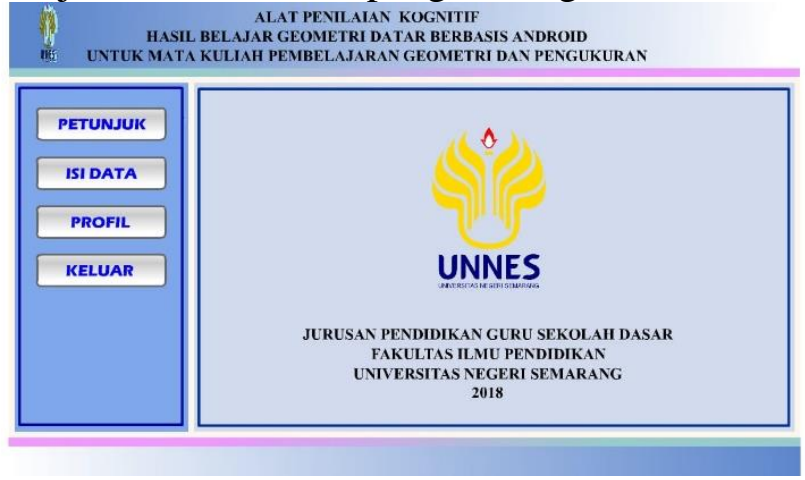

Gambar 1. Tampilan Pendahuluan

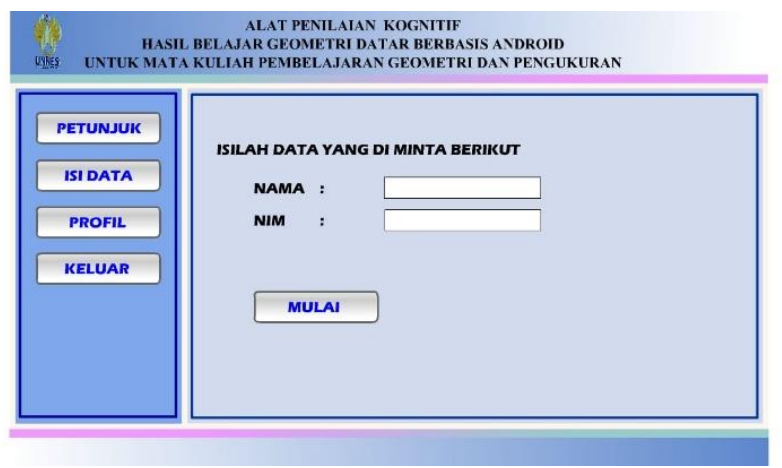

Gambar 2. Tampilan Pendahuluan (Isi Data)

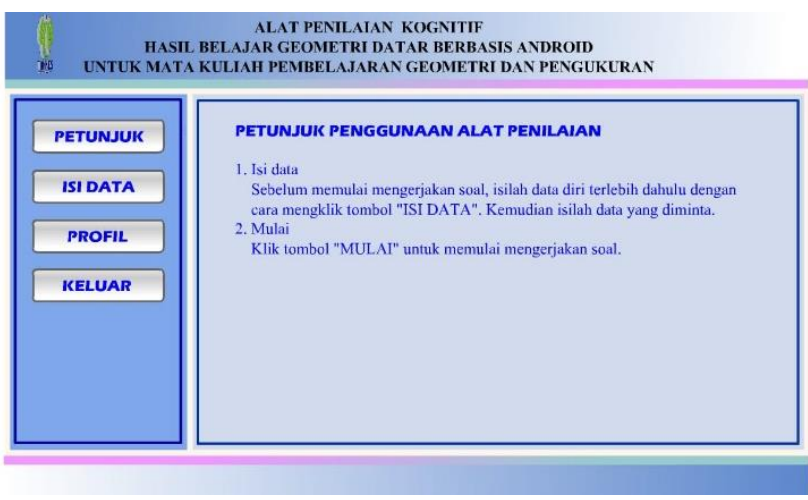

Gambar 3. Tampilan pendahuluan (petunjuk) 


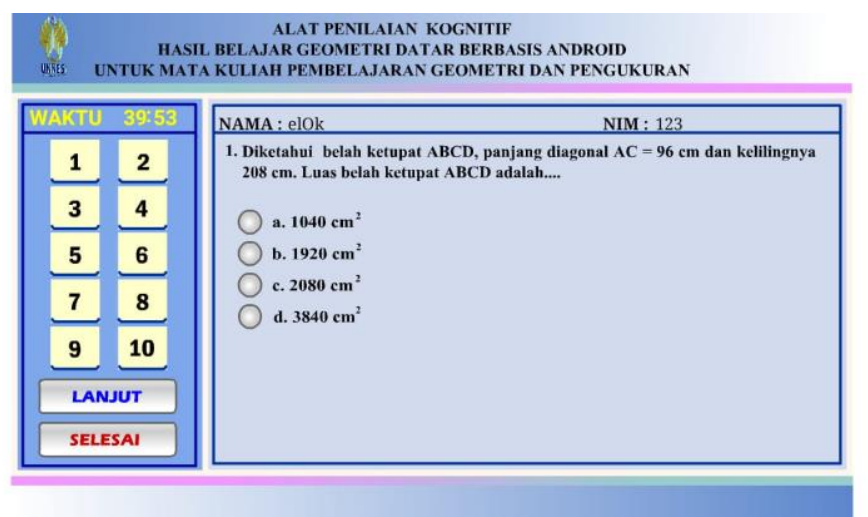

Gambar 4. tampilan inti (soal)

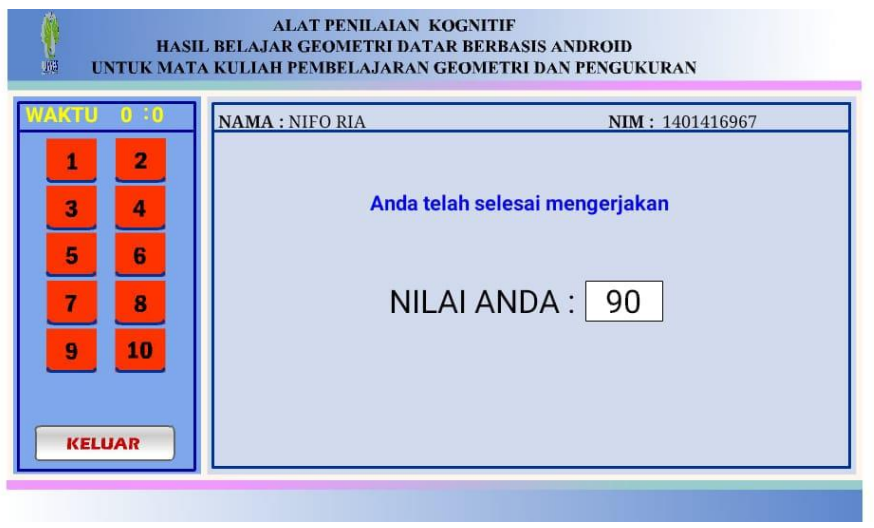

Gambar 5. Tampilan akhir

\section{Implementation (Implementasi)}

Pada tahap ini dilakukan uji coba alat penilaian berbasis android. Dilakukan uji coba terhadap 10 mahasiswa matakuliah geometri dan pengukuran. Uji coba ini bertujuan untuk mengetahui penilaian, komentar dan saran terhadap alat penilaian yang telah dikembangkan. Dari ujicoba terdapat kesalahan di dalam media, maka media tersebut direvisi terlebih dahulu sebelum diuji cobakan terhadap kelomok besar.

Setelah dilakukan revisi, alat penilaian ini diuji cobakan dalam kuliah pembelajaran geometri dan pengukuran data. Uji coba dilakukan pada tanggal 7 Juni 2018 dan 8 Juni 2018.

Pelaksanaan implementasi dilakukan dengan persiapan-persiapan yang matang. Hal-hal yang dilakukan pada persiapan implementasi ini, antara lain meng-copy aplikasi penilaian pada setiap handphone mahasiswa. Peng-copy-an dilakukan dengan bantuan shareIt. Semua handphone mahasiswa dapat diinstal aplikasi ini, kecuali yang menggunakan iphone. Setelah semua persiapan selesai, implementasi aplikasi alat peniain kognitif berbasis android segera dilakukan.

Pelaksanakan uji coba sebagai berikut:

- Menjelaskan kepada mahasiswa tata cara menggunakannya.

- Mempersilahkan mahasiswa mengerjakan soal kognitif yang ada di apikasi,

- Mengirim nilai ke dosen peneliti melalui aplikasi Whatsapp.

- Membagikan lembar angket respon mahasiswa, lalu meminta mahasiswa untuk mengisinya. 
Dalam pelaksanaan uji coba mengalami beberapa keterbatasan, antara lain:

- Pada saat mengerjakan, ada tombol yang tidak berfungsi, sehingga beberapa mahasiswa tidak dapat menulis nama mereka dengan sempurna.

- Masih terdapat salah ketik soal.

\section{E. Evaluation (Evaluasi)}

Tahap akhir dari pengembangan Alat penilaian ini adalah tahap evaluasi. Tahap evaluasi dilaksanakan dengan tujuan memperbaiki alat penilaian sebelum versi akhir diterbitkan. Pada tahap ini evaluasi akhir yaitu evaluasi sumatif untuk menilai keefektifan alat penilaian secara keseluruhan digunakan untuk penelitian lanjutan. Evaluasi pada tahap ini sebatas evaluasi terhadap tahap sebelumnya. Hasil evaluasi ini adalah:

- Alat Penilaian Kognitif ini dapat digunakan alternatif cara menilai hasil belajar.

- Respon positif yang diberikan mahasiswa ditunjukkan dengan rasa ingin tahu terhadap nilai mereka.

- Alat penilaian geometri masih perlu diperbaiki agar lebih efisien.

Alat penilaian kognitif ini dikembangkan supaya dapat digunakan sebagai alternatif cara menilai yang beda dari biasanya dan diharapkan mampu membangkitkan perasaan senang dan ingin tahu dalam mengerjakan soal. Rasa senang akan memotivasi mahasiswa giat berlatih sehingga ketrampilannya juga akan meningkat. Siswa yang berminat sikapnya akan senang terhadap pelajaran akan tampak terdorong terus untuk tekun belajar, berbeda dengan siswa yang sikapnya hanya menerima pelajaran yang guru berikan (Heriyati, 2017). Sikap belajar siswa akan terlihat sebagai suatu perasaan senang atau tidak senang, setuju atau tidak setuju, suka atau tidak suka terhadap hal-hal tertentu ketika proses pembelajaran berlangsung (Lambertus, Ambarsari \& Maonde, 2016).

\section{KESIMPULAN}

Berdasarkan hasil penelitian dan pembahasan, maka dapat disimpulkan bahwa pengembangan alat penilaian kognitif hasil belajar geometri datar berbasis android dilakukan dengan model pengembangan ADDIE. Tahap pertama yaitu tahap analisis digunakan sebagai dasar alasan dilakukannya pengembangan. Tahap kedua yaitu tahap design, yaitu mendesain alat penilaian yang akan dibuat berdasarkan hasil analisis yang dilakukan dengan membuat rancangan berupa flowchart. Penyusunan rancangan pengembangan ini bertujuan untuk menggambarkan keseluruhan isi media. Tahap ketiga yaitu development atau pengembangan, flowchart yang telah dibuat akan dikembangkan menjadi sebuah aplikasi. Untuk mengembangkan digunakan authoring tool Adobe Flash Proses pengembangan diawali dengan pembuatan template dan mengumpulkan komponenkomponen, yaitu dengan membuat background, gambar-gambar (image), teks, tombol navigasi. Tahap keempat adalah tahap implementasi yang dilakukan pada kuliah pembelajaran geometri dan pengukuran pada tanggal 7 Juni 2018 dan 8 Juni 2018. Tahap kelima yaitu tahap evaluasi dengan masukan : alat Penilaian Kognitif ini dapat digunakan alternatif cara menilai hasil belajar, respon positif yang diberikan mahasiswa ditunjukkan dengan rasa ingin tahu terhadap nilai mereka, alat penilaian geometri masih perlu diperbaiki agar lebih efisien. 


\section{REFERENSI}

Ariesto Hadi, Sutopo, (2003), Multimedia Interaktif dan Flash, PT Graha Ilmu. Yogyakarta Heriyati. 2017. Pengaruh Minat Dan Motivasi Belajar Terhadap Prestasi Belajar Matematika. Jurnal Formatif 7(1): 22-32

Irkham Ulil Albab, Yusuf Hartono, dan Darmawijoyo. (2014). Kemajuan Belajar Siswa Pada Geometri Transformasi Menggunakan Aktivitas Refleksi Geometri. Jurnal Cakrawala Pendidikan Oktober 2014, Th. XXXIII, No.3 hal 338-348. Yogyakarta: UNY

Lambertus, Ambarsari, M., Maonde, F. 2016. Pengaruh Sikap Siswa Terhadap Hasil Belajar Matematika Melalui Kombinasi Model Pembelajaran Kooperatif. Jurnal Pendidikan Matematika Volume 7 Nomor 2 hal: 105-124.

Lee.W.W. \& Owen. D.L. (2004). Multimedia-Based Instructional Design, (2nd Ed). San Francisco: Pfeiffer

Rusmiati, (2017). Pengaruh Minat Belajar Terhadap Prestasi Belajar Bidang Studi Ekonomi Siswa MA Al Fattah Sumbermulyo . UTILITY: Jurnal Ilmiah Pendidikan dan Ekonomi Volume 1, No. 1, Februari 2017: Page 21-36 ISSN 2549-1377 (Print) || ISSN 2549-1385 (Online).

Yustinus Setio Laksono, dkk. (2012). Hubungan Minat Belajar Siswa Terhadap Prestasi Belajar Matematika Siswa Dalam Pembelajaran Kooperatif Tipe STAD Menggunakan Komik. Jurnal Edukasi Matematika dan Sains, Vol. 1 No.2 